\title{
Three-dimensional Vision Development of Gun Shooting Training System in MOUT
}

\author{
Changwei Zheng \\ Academy of Armored Force Engineering \\ Beijing, China \\ Zhw_byh@163.com \\ Xiaoming Ren \\ Academy of Armored Force Engineering \\ Beijing, China \\ renxiaoming1997@163.com
}

\author{
Qing Xue \\ Academy of Armored Force Engineering \\ Beijing, China \\ Xue_qing@yeah.net \\ Yonghong Liu \\ Academy of Armored Force Engineering \\ Beijing, China \\ renxiaoming1997@163.com
}

\begin{abstract}
Gun shooting training system in MOUT is a simulation system which can replace the real equipment and ammunition. The system is taking MOUT as background, can realize shooting commander training and shooting operation training which will raise the application ability of mortar in MOUT. This paper discusses the major technical measures such as real city model, ballistic simulation and virtual soldier in MOUT vision simulation which is helpful to similar simulation system development.
\end{abstract}

Keywords-Outer ballistic simulation, Virtual solider, MOUT, Vision simulation

\section{INTRODUCTION}

Gun firing training is different from light weapon shooting training which needs the big enough place and funds in large quantities and its safety is poor and easy to cause accident. The gun shooting training system synthesizes various simulation technology, simulates the urban battlefield environment in indoor, the training people based on the simulated shooting factors such as scene in observing place and simulated effects of gun applies the shooting principles to command the shooting and input the operation data into the simulated system, further the system will assess the operation intelligently. The training system is not subjecting to the restriction of weather, place and time which can save training funds greatly and guarantee the training quality and is helpful to raise college teaching and military training.

\section{SYSTEM OUTLINE}

\section{A. System Components}

Gun shooting training system in MOUT is composed of console (one controlling computer and three computers for generating real time three-dimensional vision in MOUT are connected), six motors, one simulated distance ranger, some terminal for job inputting, three projectors and screen. The interaction between them is through real time communication, serial port and $\mathrm{A} / \mathrm{D}, \mathrm{D} / \mathrm{A}$. The system is shown in Figure.1.

\section{B. Vision System Composition}

Vision system is composed by three graph generation computers, three projectors and three screens joining together as a big screen. Graph generation computer is used in shell flight trajectory calculation, the real time of urban battlefield model, goal model and shooting effects displaying and the various scenes observed by the observation place. The graph passes through the three projectors and shown in the big screen and forms the MOUT environment of observation.

\section{Training Procedure}

According to teaching subject, teacher sets standard shooting direction, meteorology condition, shooting goal and training parameters in control computer and transmits by network to graph computer to generate correspondingly urban battlefield scenes. The trainee commanders operates the simulated distance ranger and based on regarding scene, standard shooting direction and observing position set the shooting parameters and input them to job box and carry out shooting simulation.

Simulated gun is reformed with discharge gun, added with various sensors which can gather shooting signals, table ruler and direction value signals. The trainee operates the gun, produces corresponding table ruler, direction and shooting telecommunications signals, through the collection card of $\mathrm{A} / \mathrm{D}$ to control computer. The control computer then transmits the signals that gathered to graph computer, according to direction and the table ruler of bookbinding, the chosen bullet and the medicine meteorological condition, graph computer uses the corresponding shoot table to simulate the shell flight locus with three-dimensional city topography and goal collision detection, calculates the shell explosive location and shows explosive effects and these information will return to control computer for generating the standard shooting password, compared with job box to assess the operation.

\section{Key Vision TeChnology}

Because of noise in the course measure, data from optical triangular scanners is preprocessed, which includes smoothing, removal noise and deleting exceptional points, before reconstructing surface is cable of identification clouds and process, the minimum distance is found automatically and tandem compound to acquire point group. Cut point group along a certain direction to obtain cross-section these are continuous and in a sequence. 


\section{A. City Model}

MOUT is the military operations taking place mainly in city [1]. There are many buildings which are high and low, firmly and form a comprehensive defense system of multilayers and functions. MOUT environment will greatly jeopardize the shooting effects. For high fidelity it is better to use the real terrain as the training terrain. It uses the area of $3 \times 8$ kilometers which includes the train station. By pictures and observation, MultiGen Creator software is used to set up the three dimension refined model and all the buildings possible as the fire spots have the internal model. The model is shown in Figure 2.

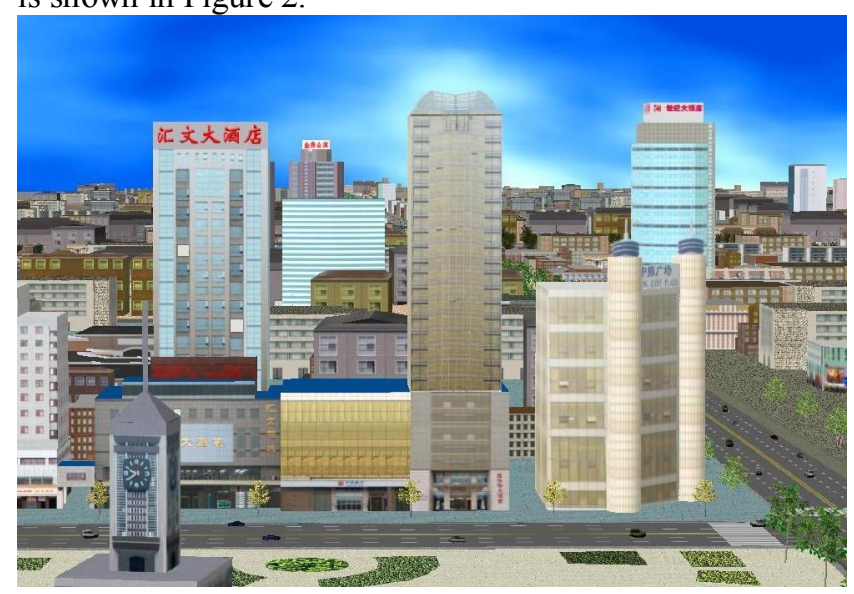

Figure 2. city model scene

\section{B. Ballistic Simulation}

Owning to many high buildings in city, shell flight is influenced easily. At the same time urban battle will set cannon in open space between buildings and solid building, setting ruler is difficult. It is trouble to rely on the law of Monte Carlo to carry out shooting effect assessment. Therefore it must carry out simulation of gun outside trajectory in order to raise systematic credibleness.

Ballistic simulation adopts the linear method, parabola with fixed point method, particle ballistic equations. The linear method supposes the aiming point is far from the real track, parabola with fixed point method uses the one or two parabola to take place the line, but this can not get the accurate track parameters. This paper adopts the shooting table merging with parabola method which fully considers the effects of crosswind and sets up the three dimensions ballistic track model.

1) Merging the projection line in shooting plane

The projection curve in shooting plane can be linked from two parabolas (ascending arc, descending arc). In [2] it proposes 3 kinds of solution to revolve parabola and this paper choose the second kind method for better real time and less error.

Setting the highest track $\mathrm{x}=\mathrm{b}$, then the expressions of parabola are:

$$
\left\{\begin{array}{l}
y=a_{1}(x-b)^{2}+c_{1} \quad \mathrm{x}<\mathrm{b} \\
y=a_{2}(x-b)^{2}+c_{2}+\Delta h(x-b) \quad \mathrm{x} \geq \mathrm{b}
\end{array}\right.
$$

When $\mathrm{x}=0, \mathrm{y}=0,\left.\frac{d y}{d x}\right|_{x=0}=\alpha$;

when $\mathrm{x}=\mathrm{b}, \mathrm{y}=\mathrm{h}$; when $\mathrm{x}=\mathrm{d}, \mathrm{y}=0$ 时 $\left.\frac{d y}{d x}\right|_{\mathrm{l}=d}=\beta$

then: $a_{1}=-\tan ^{2} \alpha / 4 h$,

$a_{2}=-\tan \beta / 2(d-2 h / \tan \beta), b=2 h / \tan \alpha, c_{1}=h$

$c_{2}=\tan \beta(d-2 h / \tan \alpha) / 2$,

$\Delta h=-h /(d-2 h / \tan \alpha)+\tan \beta / 2$

The detail is shown in [2].

2) Merging the projection line in gun horizontal plane

The factors for the shell lateral deflection in gun horizontal plane are direction spread and crosswind. Direction spread is a random value which can be expressed by bullets spread model. Crosswind produces a lateral acceleration for shell by a lateral force. The lateral deflection of shell in gun horizontal plane has an even acceleration.

From shooting table it can get the lateral trajectory angle ( the direction angle adjustment) of different shooting distance under different speeds crosswind, by this it can calculate the different acceleration that winds produce for shell, the trajectory equation in the projection plane curve in cannon gun horizontal plane is as follow:

$$
z=\frac{1}{2} a_{i} \cdot t^{2}
$$

In above formation: $\mathrm{t}$ is time of bullet flying.

$a_{i}$ is the acceleration of different winds.

\section{Virtual Solider}

In MOUT soldiers are important defensive and offensive strength whose task includes attacking designating goal, suppressing the enemy firepower and shatter enemy fortifications, eliminating enemy strength [3]. Soldier model behavior property and the three-dimensional geometry property in virtual battlefield are called as three-dimensional virtual soldier [4] (3 D Virtual Soldier). According to perception law and the visual characteristics of person, developing perception model; According to behavior features and the layered behavior theory in MOUT, developing the behavior model of virtual soldier. Then it realizes the behavior simulation of virtual soldier with the interactive simulation software DI-Guy of Boston Dynamics.

1) Model framework of virtual solider

In actual battlefield, soldier carries out environment perception through the perceptual organs and then decides the tactical behavior according to the perception. According to the research of psychology, it is the cycle of perception decision - action. Person can percept the environment changes and combining self state with knowledge to make decision, take proper reaction [5]. In virtual battlefield virtual soldiers don't need external interaction and can percept the various information and combine with task, situation, choose the proper actions. The model framework is shown in Figure.3.

Vision is the most important information channel and hearing is the complimentarily by which soldiers can judge the attributes of subjects such as location, size and so on. 
Vision model is for detecting targets based on probability theory. Hearing sensor works by a sound trigger from which the soldier can get the subject ID and location. By sensors there are much information flowing to the soldier and the soldier needs to filter this information by sensor focus.

2) Virtual solider action configuration

Virtual soldiers in DI-Guy are composed of 200 joints including 14 basic arthritics which have control of DOF by function diguy_set_action(diguyCharacterHandle handle,diguyAction action). These actions can be divided into basic gestures, aiming and marching. the actions are shown in table $1[6]$.

\section{3) Application of virtual solider}

By addition of virtual soldier as on the contrary military strength in system and confronting with trainee, virtual soldier can complete reconnaissance search, goal option and firepower preparation and shooting in battlefield, conceal, run away and take the initiative behavior as shown in Figure4.

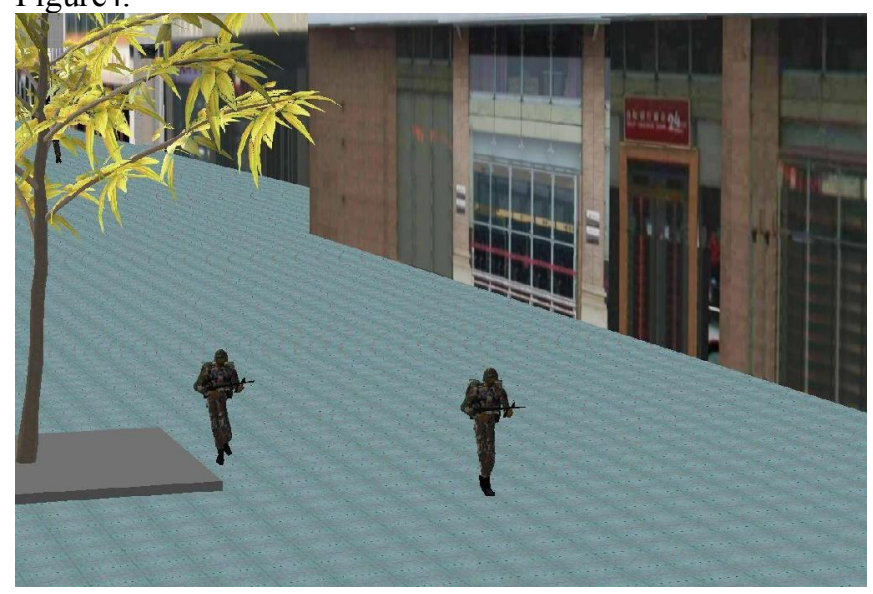

\section{SUMMARIES}

Mortar shooting training system is used successfully in Shijiazhuang and applied above-mentioned scene simulation to construct a lifelike, immersive image which has good effects. The system puts in use for many years with great economic and military benefits.

\section{REFERENCES}

[1] Liu Yongxiang. Modern MOUT[M].Beijing :Military Science Press, 1988.

[2] Zhu Minjie. Ballistic simulation of real time system [J]. System Simulation Journal, 1004-731x(2001)13, 304-306.

[3] Yao Yijun. The Research Of Perception And Decision Modeling And Simulation On Virtual Soldier Based On Bounded Rationality. [D].Master thesis of Academy of Armored Force Engineering,2010.

[4] Badler N I, Phillips C B, Webber B L. Simulating Humans: Computer Graphics, Animation, and Control. London: Oxford University Press, 1999.

[5] Che Wenbo. New dictionary of western psycholog [M]. Changchun. Jilin people's Press, 2001

[6] Boston Dynamics Inc.DI-Guy4 User Manual[M]. Boston Dynamics Inc. 2000 .

Figure 4. virtual solider searching enemy

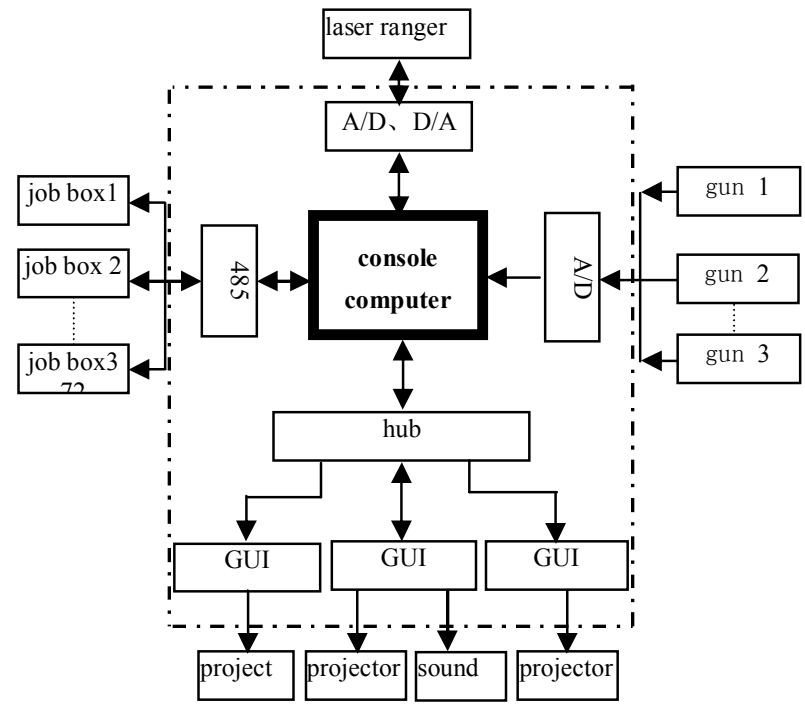

Figure 1. composition of system 


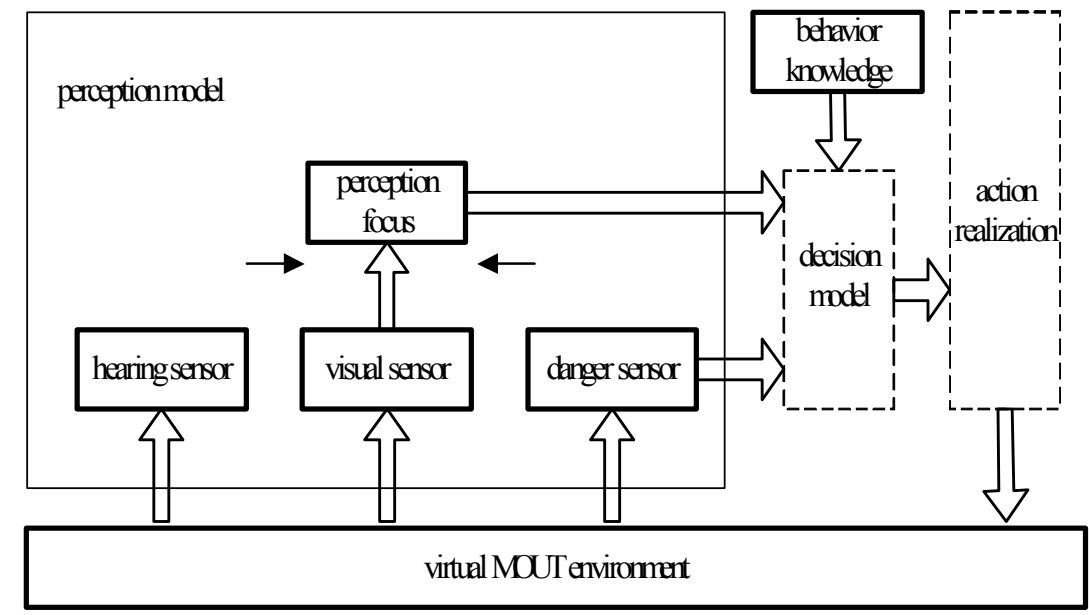

Figure 3. model framework of virtual solider

TABLE I. VIRTUAL SOLIDER ACTION

\begin{tabular}{|c|c|c|c|}
\hline Action & Action ID & Action & Action ID \\
\hline standing & SOLDIER_STAND_READY & $\begin{array}{c}\text { backward } \\
\text { searching } \\
\text { in low }\end{array}$ & SOLDIER_NL_WALK_LO_BACK \\
\hline $\begin{array}{c}\text { kneeling } \\
\text { position }\end{array}$ & SOLDIER_KNEEL_READY & $\begin{array}{c}\text { running } \\
\text { forward }\end{array}$ & SOLDIER_JOG \\
\hline $\begin{array}{c}\text { dropping } \\
\text { down }\end{array}$ & SOLDIER_PRONE_READY & $\begin{array}{c}\text { crowning } \\
\text { forward }\end{array}$ & SOLDIER_CRAWL \\
\hline death & SOLDIER_DEAD & $\begin{array}{c}\text { aiming in } \\
\text { standing }\end{array}$ & SOLDIER_STAND_AIM \\
\hline $\begin{array}{c}\text { forward } \\
\text { searching }\end{array}$ & SOLDIER_WALK & $\begin{array}{c}\text { aiming } \\
\text { on kneel }\end{array}$ & SOLDIER_KNEEL_AIM \\
\hline
\end{tabular}

